\title{
The effects of targeted deletion of the aromatase enzyme on prostatic contractile responses to noradrenaline in mice
}

\author{
Katherine T Gray, Jennifer L Short, Evan R Simpson ${ }^{\mathbf{1}}$ and Sabatino Ventura \\ Prostate Research Co-operative, Victorian College of Pharmacy, Monash University, 381 Royal Parade, Parkville, Victoria 3052, Australia \\ ${ }^{1}$ Prince Henry's Institute of Medical Research, Monash Medical Centre, 246 Clayton Road, Clayton, Victoria 3168, Australia \\ (Correspondence should be addressed to S Ventura; Email: sab.ventura@vcp.monash.edu.au)
}

\begin{abstract}
This investigation aimed to see whether a change in the oestrogen to androgen ratio alters prostate contractility. Isolated organ bath studies using prostates from aromatase knockout (ArKO) mice which were homozygous $(\mathrm{ArKO}-/-)$ and heterozygous $(\mathrm{ArKO}+/-)$ for the disrupted aromatase cyp19 gene and wild-type littermates $(\mathrm{ArKO}+/+)$ were conducted. The distribution of noradrenergic nerves was visualized using the sucrose-potassium phosphate-glyoxylic acid method. ArKO $-/-$ mice had increased prostate weights compared with ArKO + / + mice. Frequency-response curves to electrical field stimulation (EFS; $0.5 \mathrm{~ms}$ pulse duration, $60 \mathrm{~V}, 0 \cdot 1-20 \mathrm{~Hz}$ ) yielded frequency-dependent contractions, while noradrenaline $(10 \mathrm{nM}-1 \mathrm{mM})$ and tyramine $(1 \mu \mathrm{M}-1 \mathrm{mM})$ produced

concentration-dependent contractions. Prazosin $(0 \cdot 3 \mu \mathrm{M})$ attenuated the responses induced by noradrenaline and EFS in all mice $(P \leq 0 \cdot 019, n=5-7)$, while cocaine $(10 \mu \mathrm{M})$ attenuated the responses evoked by tyramine $(P<0 \cdot 001, n=6)$. There were no genotype differences in EFS- and noradrenaline-induced responses $(P \geq 0 \cdot 506, n=10-13)$. Prostates from ArKO $-/-$ and $\mathrm{ArKO}+/-$ mice were more sensitive to tyramine than prostates from ArKO $+/+$ mice $(P<0 \cdot 001, n=11-13)$. Dense adrenergic innervation of the prostate was similar in all mice. These results suggest that although the absence of aromatase increases prostatic growth, this translates only to a subtle and selective increase in contractility in mature mice.

Journal of Endocrinology (2007) 195, 495-502
\end{abstract}

\section{Introduction}

Benign prostatic hyperplasia $(\mathrm{BPH})$ is predominantly a stromal disease resulting in a non-malignant enlargement of the prostate gland (Bartsch et al. 1979). BPH has both static and dynamic components associated with its development. The static component arises from hyperplasia of both the glandular and stromal tissue, while the dynamic component arises from increased stromal contractility mediated through increased noradrenergic activation of $\alpha_{1}$-adrenoceptors. Both components of $\mathrm{BPH}$ increase prostatic pressure on the urethra and bladder, resulting in troublesome lower urinary tract symptoms. Androgen-induced prostate growth is well known to induce the static component of $\mathrm{BPH}$ but the role that androgens play in mediating the dynamic component is less certain. An androgen-induced change in $\alpha_{1}$-adrenoceptor density and/or function has been postulated to contribute to the development of the dynamic component (Yamada et al. 1987, Walden et al. 1999). To the contrary, it has been shown that androgen deprivation does not alter $\alpha_{1}$-adrenoceptor density in the rat ventral prostate (Lacey et al. 1996).

The relative oestrogen dominance observed in older males, compared with younger males, has been hypothesized to be a causative factor in the development of $\mathrm{BPH}$. With increasing age, it is widely accepted that there is an increase in the ratio of oestradiol to dihydrotestosterone; concurrently, there is a significant increase in prostate size and the proportion of stroma to epithelium (Krieg et al. 1993, Farnsworth 1999, Shibata et al. 2000). Whether this increased stroma translates to an increase in contractility is not known. Oestrogen receptor numbers have also been shown to change with the onset of BPH (Schulze \& Claus 1990). Low numbers of oestrogen receptors are seen in the stroma of normal prostates, high concentrations in stromal tissue from patients with non-obstructive $\mathrm{BPH}$ and no oestrogen receptors in the stroma of prostates from men with severe obstructive BPH (Schulze \& Claus 1990). This study concluded that oestrogen receptors may not mediate the stromal growth observed in $\mathrm{BPH}$, however, the increase in oestrogen receptors in the stroma of non-obstructive BPH tissues suggests that oestrogen receptors may be important in the initiation of $\mathrm{BPH}$ (Schulze \& Claus 1990).

The role that oestrogens play in prostate contractility is unclear. Sex hormones have been shown to have varied effects in cell lines derived from individuals suffering BPH. Stromal cells from some patients were unchanged after treatment with oestradiol and testosterone, while stromal cells from other patients displayed a more contractile phenotype (Smith et al. 2000). Previously, it has been shown that the expression of smooth muscle cell markers is influenced by oestradiol treatment, however, the same treatment had little impact on 
the growth of smooth muscle cell cultures (Zhang et al. 1997). A recent study, also using cell culture techniques, showed that at certain concentrations, testosterone, oestradiol and dihydrotestosterone, either alone or in combination, influenced the agonist-induced activity of human cultured prostatic stromal cells through regulation of $\alpha$ - and $\beta$-adrenoceptors and/or signal transduction pathways (Nguyen et al. 2007).

This study investigates the role of oestrogen modulation on prostate contractility in vitro using prostate tissue taken from aromatase knockout (ArKO) mice. Oestrogen synthesis from androgens is catalysed by the enzyme aromatase cytochrome P450 (Means et al. 1989). Disruption of the aromatase gene prevents the biosynthesis of endogenous oestrogens and allows investigation into whether the absence of oestrogen alters prostate contractility in mature mice. It is well documented that homozygous null ArKO mice have no detectable oestradiol, increased testosterone and dihydrotestosterone levels and exhibit an increase in prostate size, compared with wild-type controls (Fisher et al. 1998, McPherson et al. 2001). Despite this, it is still not known whether this increase in size corresponds to any change in prostate contractility. This study aims to determine whether the absence of oestrogen through disruption of the aromatase gene leads to a change in prostate contractility.

\section{Materials and Methods}

\section{Animals}

Adult male ArKO mice were generated as previously described (Fisher et al. 1998). Briefly, exon 9 of the mouse cyp 19 gene was selected for disruption by the insertion of a neomycin-resistant cassette between the EcoRV and XhoI restriction sites. Heterozygous breeding pairs were used to produce mice which were homozygous $(\mathrm{ArKO}-/-)$ and heterozygous $(\mathrm{ArKO}+/-$ ) for the gene disruption, as well as age-matched wild-type $($ ArKO $+/+$ ) littermate controls. Mice were obtained and bred on a mixed C57Bl6J and J129 background and were routinely genotyped by PCR using genomic DNA extracted from tail tissue biopsies. Mice were housed in the Victorian College of Pharmacy animal house at $22^{\circ} \mathrm{C}$ and exposed to a photoperiod of $12 \mathrm{~h}$ light: $12 \mathrm{~h}$ darkness. Mice had free access to water and soy-free rat and mouse chow (Specialty Feeds, Glen Forrest, Australia). At 8-16 weeks of age, mice were weighed before being killed by cervical dislocation. Prior approval for animal experimentation was obtained from the Monash University Standing Committee of Animal Ethics in Animal Experimentation; ethics number: VCPA 2005/3.

\section{Prostate dissection}

A lower abdominal incision was made exposing the male urinogenital tract of the mouse. The penile muscles were cut posteriorly to expose the prostate glands, and the whole prostate was carefully dissected and placed in a Petri dish containing Krebs-Henseleit solution (mM: $\mathrm{NaCl} 118 \cdot 1, \mathrm{KCl} 4 \cdot 69$, $\mathrm{KH}_{2} \mathrm{PO}_{4} 1 \cdot 2, \mathrm{NaHCO}_{3} 25 \cdot 0$, glucose $11 \cdot 7, \mathrm{MgSO}_{4} 1 \cdot 1$ and $\mathrm{CaCl}_{2} 2 \cdot 5$ ) where excess fat and connective tissue were removed. Prostates were weighed at the conclusion of experiments.

\section{Isolated organ bath studies}

Due to the size of the mouse prostate, the results presented in this work were obtained from whole prostate tissues rather than any specific individual lobes. Whole prostate tissues were mounted in $10 \mathrm{ml}$ water-jacketed glass organ baths containing KrebsHenseleit solution, maintained at $37^{\circ} \mathrm{C}$ and bubbled with $5 \%$ $\mathrm{CO}_{2}$ in $\mathrm{O}_{2}$. Due to the multi-directional alignment of the smooth muscle fibres within the prostate, it was not possible to orientate the tissue in a specific direction; rather, one end of the prostate was attached to a Perspex tissue holder and the other to a Grass FTO3C transducer for recording of isometric contractions of the prostatic smooth muscle. Developed force was recorded via a PowerLab data acquisition system (Chart 3.6) which was run on an HP Compaq dc7100 personal computer. Preparations were equilibrated for $60 \mathrm{~min}$ under a resting tension of $0 \cdot 4-0 \cdot 7 \mathrm{~g}$. To ensure tissue viability, prostatic tissues were electrically stimulated during the equilibration period via two vertical parallel platinum electrodes incorporated in the tissue holder, which was connected to a Grass S88 stimulator. Stimulation parameters during equilibration were $0.5 \mathrm{~ms}$ pulse duration, $60 \mathrm{~V}$ at $0.01 \mathrm{~Hz}$.

Electrical field stimulation To assess nerve-mediated contractions, frequency-response curves $(0.5 \mathrm{~ms}$ pulse duration, $60 \mathrm{~V}, 0 \cdot 1-20 \mathrm{~Hz}$ ) to electrical field stimulation were constructed using a frequency progression ratio of approximately one-third of a log unit. The endogenous firing rates of the nerves innervating the mouse prostate are not known. Thus, using a wide range of frequencies $(0 \cdot 1-20 \mathrm{~Hz})$ ensures any endogenous firing frequencies are covered in our experimental protocol. Furthermore, we have previously shown these parameters to be tetrodotoxin sensitive and therefore specific for depolarizing nerves (Gray \& Ventura 2005). Trains of pulses were delivered at intervals of $10 \mathrm{~min}$. Each train consisted of 10 pulses at low frequencies $(\leq 1 \mathrm{~Hz})$ or was for $10 \mathrm{~s}$ duration at higher frequencies $(\geq 1 \mathrm{~Hz})$. An initial frequency-response curve was constructed to determine the contractile response of the tissue at each frequency. Following the initial frequency-response curve, tissues were washed and exposed to the $\alpha_{1}$-adrenoceptor antagonist, prazosin $(0 \cdot 3 \mu \mathrm{M})$ for $60 \mathrm{~min}$ before a second frequency-response curve was constructed. An appropriate time control curve was also constructed in which isolated prostates were not exposed to antagonist prior to the second frequency-response curve.

Agonist studies For noradrenaline studies, tissues were not electrically field stimulated after the 60-min equilibration period but instead, were exposed to a priming dose of $0 \cdot 1 \mathrm{mM}$ noradrenaline. Once the contractile response of the tissues had reached a plateau, the tissues were washed with four 
to five times the bath volume and allowed $30 \mathrm{~min}$ to recover. Following this, discrete concentration-response curves to noradrenaline (10 $\mathrm{nM}-1 \mathrm{mM})$ were constructed using a dose progression ratio of approximately half a $\log$ unit. Discrete concentration-response curves were used rather than cumulative concentration-response curves as the mouse prostate is not able to consistently sustain the prolonged contractions required for the construction of cumulative concentration-response curves. Once the contractile response to each concentration of noradrenaline had reached a maximum, tissues were washed with four to five times the bath volume and allowed $10 \mathrm{~min}$ to recover before the next concentration was applied. If no response was observed after $30 \mathrm{~s}$, the tissues were washed and allowed $10 \mathrm{~min}$ to recover. Following the initial concentrationresponse curve, tissues were exposed to prazosin $(0 \cdot 3 \mu \mathrm{M})$ for 60 min before a second concentration-response curve was constructed. During the second curve, prazosin was replaced after each bath wash. An appropriate time control curve was also constructed where the tissues were not exposed to prazosin during the second concentration-response curve.

Concentration-response curves to the indirectly acting sympathomimetic, tyramine $(1 \mu \mathrm{M}-1 \mathrm{mM})$ were also constructed using the same protocol but without a priming dose being administered. To test whether tyramine was acting indirectly, the second concentration-response curve was constructed in the presence of the neuronal uptake inhibitor cocaine $(10 \mu \mathrm{M})$.

\section{Histochemistry}

Catecholamine fluorescence Tissue sections were stained for noradrenaline using a method modified from that described by de la Torre \& Surgeon (1976). Fresh tissues were placed in Tissue-Tek (optimal cutting temperature (OCT) embedding compound) and frozen immediately at $-20^{\circ} \mathrm{C}$. Sections were randomly cut $(12 \mu \mathrm{m})$ throughout the whole prostate using a cryostat (Leica CM 1850) at $-20{ }^{\circ} \mathrm{C}$, thawed onto gelatine-coated slides and left to airdry for $60 \mathrm{~min}$ prior to staining. Slide-mounted sections from each genotype were dipped in a freshly prepared sucrosepotassium phosphate-glyoxylic acid (SPG) solution containing $0 \cdot 20 \mathrm{M}$ sucrose, $0 \cdot 24 \mathrm{M} \mathrm{KH}_{2} \mathrm{PO}_{4}$ and $1 \cdot 0 \%$ $(\mathrm{w} / \mathrm{v})$ glyoxylic acid (Sigma) adjusted to $\mathrm{pH} 7 \cdot 4$ with $5 \cdot 0 \mathrm{M}$ $\mathrm{NaOH}$, three times for $1 \mathrm{~s}$ each time before being left to airdry for $20 \mathrm{~min}$. The slides were then heated in an oven at $80^{\circ} \mathrm{C}$ for $5 \mathrm{~min}$, mounted in paraffin oil, coverslipped and heated on an $80^{\circ} \mathrm{C}$ hotplate for $90 \mathrm{~s}$. The sections were examined with an Olympus BX60 fluorescence microscope (Olympus, Tokyo, Japan) fitted with an Olympus mercury burner light source attachment and an Olympus U-MNV filter cube consisting of a dichroic mirror, DM455 a BP400410 exciter filter and a BA455 barrier filter. A SPOT RT slider digital camera and SPOT RT software (v. 3.5) (Diagnostic instruments, Sterling Heights, MI, USA) run on a Compaq 9500 personal computer were used to record exposure times and take photomicrographs of the sections.

\section{Analysis of data}

Isolated organ bath studies All data analyses were carried out using GraphPad Prism (v. 4.0; GraphPad, San Diego, CA, USA). Results are expressed as mean \pm s.E.M., where the value of $n$ represents the number of experimental animals used. In all data analyses, $P \leq 0 \cdot 05$ was considered significant.

Mouse, prostate and percentage prostate weights were analysed by one-way ANOVA with a Bonferroni post-test for multiple comparisons.

The peak force (g) of electrical field stimulation- or agonist-induced contractile responses was measured at each frequency or concentration in each genotype and a mean frequency- or concentration-response curve constructed. Mean frequency- or concentration-response curves were constructed by pooling data from experiments using tissues from at least five mice.

In frequency-response graphs, the mean contractile responses in the presence of prazosin were compared with the previously obtained control responses (no drug). Differences in frequency-response curves were analysed by a two-way repeated measure ANOVA. $P$ values used to evaluate statistical significance were the probabilities of a significant interaction between frequency and treatment. Concentration-response curves compared the contractile response with increasing concentrations of noradrenaline or tyramine in the absence and presence of prazosin or cocaine respectively. Raw data were expressed as a percentage of the maximum response obtained in the control concentrationresponse curve. Differences were analysed by a two-way repeated measure ANOVA. $P$ values were the probabilities of a significant interaction between concentration and treatment.

In order to determine whether responses differed between genotypes, control responses from each genotype to electrical field stimulation or each of the agonists were plotted on single graphs and analysed using a two-way repeated measure ANOVA. $P$ values were the probabilities of a significant difference between genotype and frequency or concentration.

Maximum agonist-induced responses from each genotype were analysed by one-way ANOVA with a Bonferroni posttest for multiple comparisons. $P$ values were the probability of a significant difference in the magnitude of response from different genotypes.

In addition, to ensure any changes in prostate weight were not influencing the responses observed, maximum noradrenaline- and tyramine-induced contractile responses were expressed as the force produced per gram weight of prostate tissue. Maximum responses from each genotype were then reanalysed by one-way ANOVA with a Bonferroni post-test for multiple comparisons. $P$ values were the probability of a significant difference in genotype and the force produced per gram weight of prostate tissue.

Histochemistry The density of noradrenaline-containing nerve fibres innervating the prostate was quantified by 
measuring the fluorescent light intensity emitted by SPGstained prostate sections. The SPOT RT slider digital camera and SPOT RT software (v. 3.5) were used to determine the exposure time needed for different microscopic fields of view to reach an arbitrary level of fluorescence intensity. The reciprocal of the determined exposure time was then calculated to give a measure offluorescence intensity, as these measures are inversely proportional. This was determined in four to five fields of view from each section and at least 14 sections from various regions of the prostate were used for each tissue studied. The mean intensity of stained nerve fibres per cross-sectional field of view for each mouse of each genotype was determined and the mean and S.E.M. of these values for each genotype was calculated. Prostates from each genotype were processed in parallel allowing mean values to be compared by one-way ANOVA.

\section{Drugs and vehicle solutions}

The following drugs were used: $(-)$ arterenol (noradrenaline) bitartrate, cocaine hydrochloride, prazosin hydrochloride and tyramine hydrochloride (Sigma).

Noradrenaline and tyramine were dissolved and diluted to the required concentrations in a catecholamine diluent ( $\mathrm{mM}$ : $\mathrm{NaCl} 154 \cdot 0, \mathrm{NaH}_{2} \mathrm{PO}_{4} 1 \cdot 2$ and ascorbic acid 0.2). Prazosin and cocaine were dissolved and diluted to required concentrations in distilled water.

\section{Results}

\section{Mouse and prostate weights}

Mean mouse weights for the different genotypes are shown in Fig. 1A. Comparison of the mouse weights between each genotype showed no difference with regards to genotype $(P=0 \cdot 874, n=33-37$, one-way ANOVA; Fig. 1A). Mean prostate weights for the different genotypes are shown in Fig. 1B. Prostates from ArKO $-/-$ mice were $~ 30 \%$ heavier than prostates taken from ArKO $+/+$ mice $(P<0 \cdot 05, n=33-37$, one-way ANOVA). When expressed as a percentage of body weight prostates from ArKO $-/$ - mice were still $\sim 30 \%$ heavier than prostates taken from $\mathrm{ArKO}+/+$ mice $(P<0 \cdot 01$, $n=33-37$, one-way ANOVA; Fig. 1C).

\section{Isolated organ bath studies}

Responses to electrical field stimulation Time control curves performed in the absence of drug administration demonstrated that the contractile responses of isolated mouse prostates to electrical field stimulation were reproducible over time regardless of genotype $(P \geq 0.951, n=6)$. Increasing frequency resulted in increased contractile responses from isolated prostates which were not different between the different genotypes $(P=0 \cdot 506, n=12-13)$. Contractile responses expressed as the force produced per gram weight of prostate tissue were still not different between genotypes
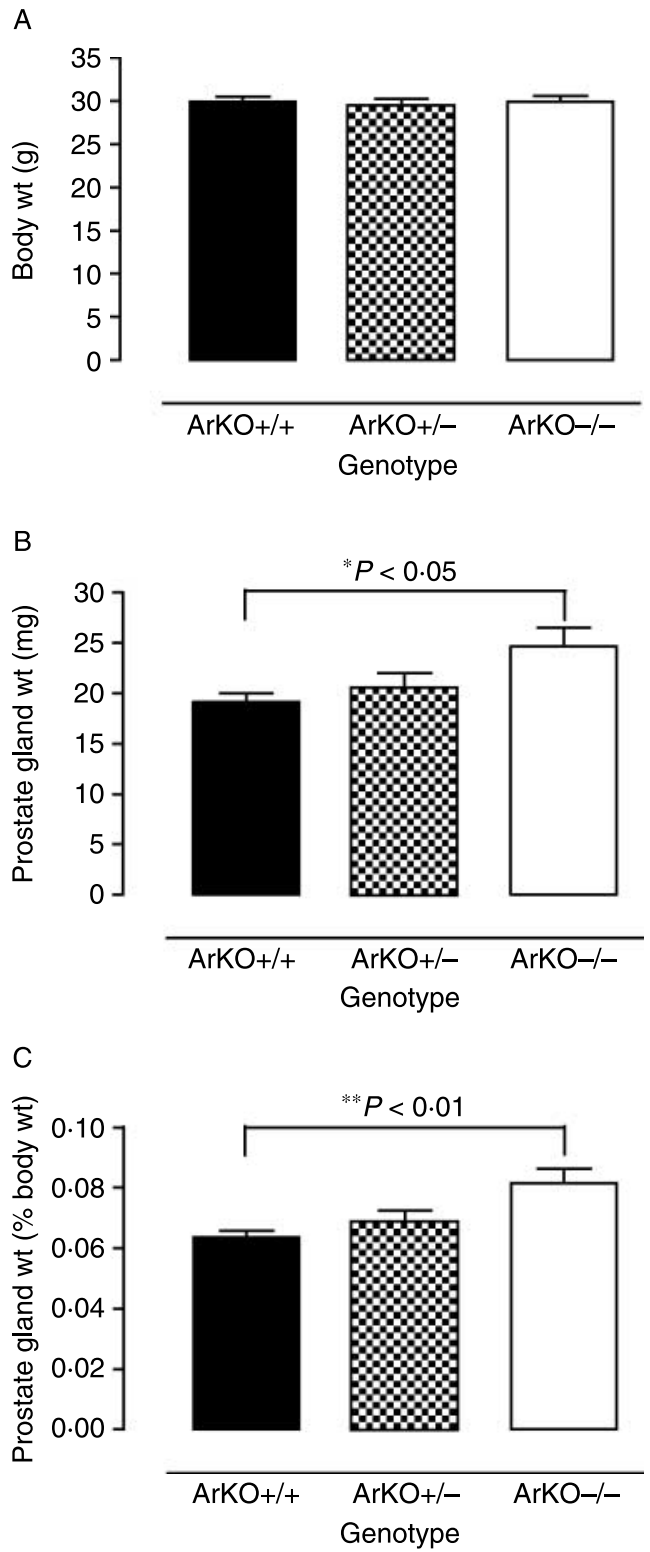

Figure 1 (A) Body weight (g), (B) prostate gland weight (mg) and (C) prostate gland weight (percentage body weight) of ArKO $+/+$ $(n=33$; solid bars), ArKO +/- $(n=36$; chequered bars) and ArKOI- $(n=37$; open bars $)$ mice. Error bars represent the s.E.M. $P$ values represent the probability of a significant difference between weight and genotype (one-way ANOVA). ${ }^{* *} P<0 \cdot 01,{ }^{*} P<0 \cdot 05$.

$(P=0.493, n=12-13)$. The $\alpha_{1}$-adrenoceptor antagonist prazosin $(0.3 \mu \mathrm{M})$ was able to significantly reduce the responses to electrical field stimulation at frequencies $>1 \mathrm{~Hz}$ in all genotypes $(P \leq 0 \cdot 022, n=6-7)$.

Agonist studies Time control curves performed in the absence of blocking drugs demonstrated that the contractile responses of isolated mouse prostates to exogenous 
A

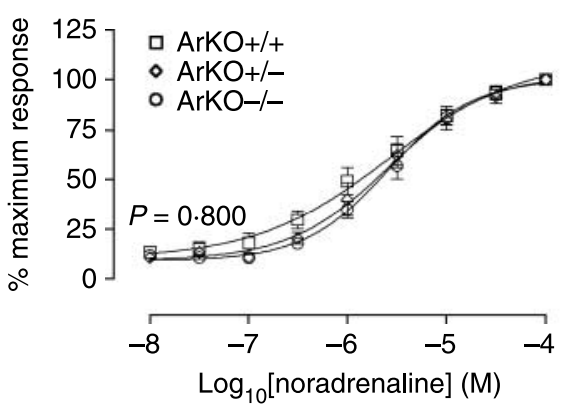

B

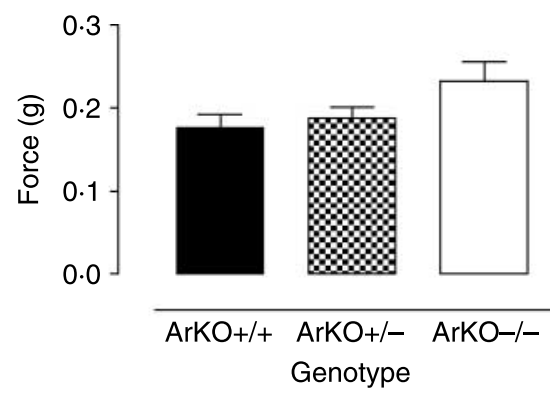

Figure 2 (A) Mean contractile responses to exogenous administration of noradrenaline on unstimulated preparations of ArKO $+/+(\square)$, ArKO $+/-(\diamond)$ and ArKO $-/-(O)$ prostates. Points represent mean force from 10 to 12 prostates. Error bars represent the S.E.M. $P$ Values represent the probability of a significant interaction between genotype and response (one-way ANOVA).

(B) Maximum responses to noradrenaline at $0.1 \mathrm{mM}$ in ArKO $+/+$ (solid bars), ArKO $+/-$ (chequered bars) and ArKO-/- (open bars) prostates.

administration of noradrenaline were reproducible over time regardless of genotype $(P \geq 0 \cdot 544, n=5-6)$. Exogenously administered noradrenaline (10 $\mathrm{nM}-1 \mathrm{mM})$ elicited concentration-dependent responses in isolated preparations of the mouse prostate from all genotypes (Fig. 2A), with maximum responses of $0 \cdot 18 \pm 0 \cdot 02,0 \cdot 19 \pm 0 \cdot 01$ and $0 \cdot 23 \pm 0 \cdot 02 \mathrm{~g}$ in $\mathrm{ArKO}+/+, \mathrm{ArKO}+/-$ and ArKO $-/-$ respectively, at a concentration of $0.1 \mathrm{mM}$ (Fig. 2B). Maximum contractile responses of mouse prostates from each genotype were not significantly different when expressed as either raw data or force produced per gram weight of tissue $(P \geq 0 \cdot 091$, $n=10-12)$. Similarly, concentration-response curves when expressed as a percentage of maximum response were not different between genotypes $(P=0 \cdot 800, n=10-12$; Fig. 2A). Prazosin $(0.3 \mu \mathrm{M})$ was able to significantly attenuate the contractile responses induced by noradrenaline in prostates taken from mice of each genotype $(P \leq 0 \cdot 001, n=5-6)$.

A

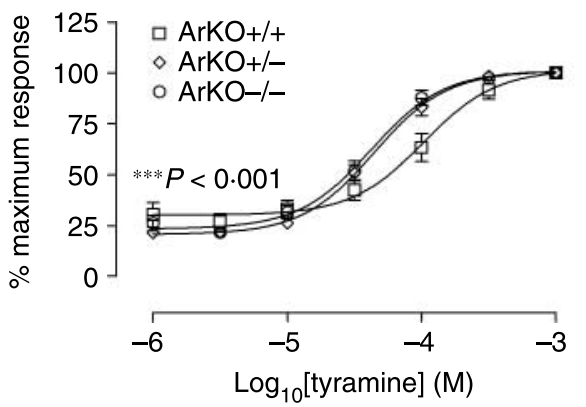

Time control curves performed in the absence of cocaine demonstrated that the contractile responses of isolated mouse prostates to tyramine were slightly reduced over time regardless of genotype $(P \leq 0 \cdot 022, n=5-7)$. Endogenous release of neurotransmitter induced by exogenous administration of tyramine $(1 \mu \mathrm{M}-1 \mathrm{mM})$ resulted in concentration-dependent contractions of the mouse prostate which were significantly different between genotypes $(P<0 \cdot 001, n=11-13$; Fig. 3A). Prostates taken from $\mathrm{ArKO}+/+$ mice were approximately threefold less sensitive to tyramine than prostates taken from ArKO - / and $\mathrm{ArKO}+/-$ mice. Maximum responses of $0 \cdot 13 \pm 0 \cdot 02 \mathrm{~g}$ $(\mathrm{ArKO}+/+), 0 \cdot 13 \pm 0 \cdot 01 \mathrm{~g}(\mathrm{ArKO}+/-)$ and $0 \cdot 14 \pm$ $0.01 \mathrm{~g}(\mathrm{ArKO}-/-)$ were induced by tyramine at $1.0 \mathrm{mM}$, and did not differ between genotypes when expressed as either raw data or the maximum force produced per gram weight of prostate tissue $(P \geq 0 \cdot 309$,

B

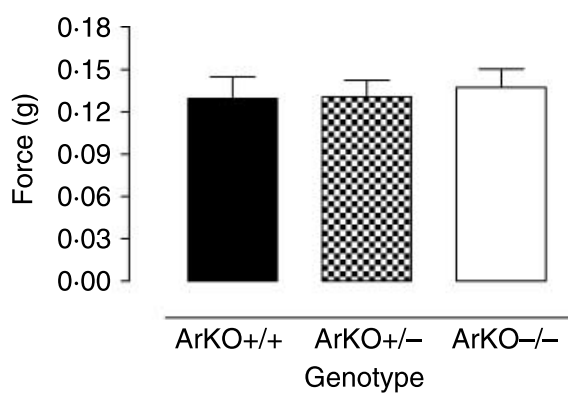

Figure 3 (A) Mean contractile responses to exogenous administration of tyramine on unstimulated preparations of $\mathrm{ArKO}+/+(\square)$, ArKO $+/-(\diamond)$ and ArKO $-/-(O)$ prostates. Points represent mean force from 11 to 13 prostates. Error bars represent the S.E.M. $P$ values represent the probability of a significant interaction between genotype and response (two-way repeated measure ANOVA). ${ }_{* * *} P<0 \cdot 001$. (B) Maximum responses to tyramine at $1 \cdot 0 \mathrm{mM}$ in ArKO $+/+$ (solid bars), ArKO $+1-$ (chequered bars) and ArKO $-/-$ (open bars) prostates. 
$n=11-13$; Fig. $3 \mathrm{~B})$. Cocaine $(10 \mu \mathrm{M})$ was able to inhibit the responses induced by tyramine in all genotypes $(P<0 \cdot 001, n=5-7)$.

\section{Histochemistry}

Catecholamine fluorescence Adrenergic nerves positively stained for noradrenaline by the SPG method were distributed throughout the stroma in prostates from all genotypes (Fig. 4). Staining patterns were of similar density in $\mathrm{ArKO}+/+$, $\mathrm{ArKO}+/-$ and $\mathrm{ArKO}-/-$ tissues with no significant difference in the determined fluorescence intensity across all genotypes $(P=0 \cdot 516, n=6$; Fig. 4). No staining was observed in the epithelial cells of prostates from mice of any genotype.

\section{Discussion}

This paper examines the role of oestrogen on prostate contractility and development. We have previously shown the mouse to be a good model of human prostate function (Gray \& Ventura 2005, 2006). Despite observations that the mouse does not develop hyperplasia with increasing age and that the muscle to epithelial ratio of the mouse prostate is different to that observed in the human, the mechanisms underlying prostatic contractions and relaxation are similar to those observed in the human.

The increased growth of the prostate gland induced by the targeted disruption of the aromatase gene in mice has been well documented. The prostate/bladder complex is $~ 50 \%$ larger in ArKO - / - mice than ArKO + / + mice (Fisher et al. 1998), while the wet weight of the ventral prostate lobe is $46-60 \%$ larger in $\mathrm{ArKO}-/-$ mice compared with wild-type littermates, depending on the age of the mice (McPherson et al. 2001). Our observations that whole prostates from ArKO $-/-$ mice are heavier than prostates from wild-type littermates is consistent with the literature, and highlights the role played by hormones in modulating prostate growth. The increased prostate weight observed has been shown to be due to hyperplasia of the entire organ rather than hyperplasia of particular compartments (McPherson et al. 2001). The epithelial to stromal ratio in our study was not obviously altered in ArKO - / - sections compared with $\mathrm{ArKO}+/+$ sections. However, due to the dark slide background associated with SPG histochemistry, this ratio could not be conclusively measured.

Previously, serum oestradiol levels have been shown to be below the level of detection in both $\mathrm{ArKO}-/-$ and ArKO $+/+$ mice (Fisher et al. 1998). Testosterone, and prolactin levels are significantly increased in ArKO-/mice when compared with $\mathrm{ArKO}+/+$ mice, though in the prostate tissue itself, only dihydrotestosterone levels are increased (McPherson et al. 2001). This elevated level of dihydrotestosterone is, in part, responsible for the enlarged prostates observed in $\mathrm{ArKO}-/-$ mice. As oestrogen has also been shown to have a direct inhibitory effect on prostate growth (Jarred et al. 2000), the absence of oestrogen in the ArKO $-/-$ mouse would also appear to contribute to
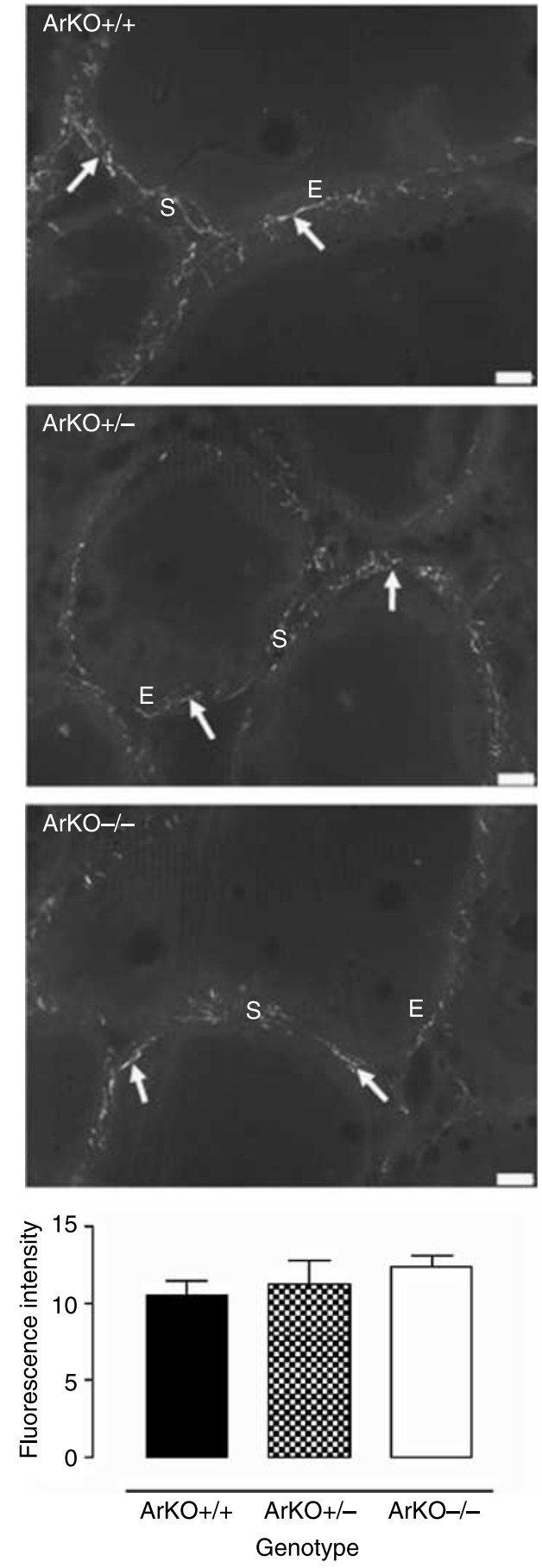

Figure 4 Representative photomicrographs illustrating the distribution of noradrenergic nerves $(n=6)$ in SPG-stained sections of mouse prostate taken from ArKO $+/+$, ArKO $+/-$ and ArKO - /mice. Positive staining indicated by arrows. S, fibromuscular stroma; E, glandular epithelium. Scale bar $=100 \mu \mathrm{m}$. Below: mean fluorescence intensity from fresh slide-mounted SPG-stained sections of prostates from $\mathrm{ArKO}+/+(n=6$; solid bars $), \mathrm{ArKO}+/-$ $(n=6$; chequered bars $)$ and ArKO $-/-(n=6$; open bars) mice. 
the observed increase in prostate growth. However, the observation that serum oestradiol levels were below the level of detection in both ArKO $+/+$ and ArKO $-/-$ mice (Fisher et al. 1998), indicates that any changes in intraprostatic oestradiol concentrations might also be too small to be detected or induce a change in prostate contractility.

Changes in hormone levels in the aging male have been shown to result in an increase in the oestrogen to androgen ratio with increasing age (Krieg et al. 1993, Belanger et al. 1994, Shibata et al. 2000, Tan et al. 2003). This increased ratio appears to correlate with the onset of prostatic disease and despite conflicting reports as to whether functional intraprostatic aromatase exists (Kaburagi et al. 1987, Brodie et al. 1990, Matzkin \& Soloway 1992, Hiramatsu et al. 1997, Ellem et al. 2004), it has been suggested that aromatase inhibitors may be a useful pharmacological tool for the treatment of $\mathrm{BPH}$ (Habenicht \& el Etreby 1991). Proliferation of smooth muscle, as detected by positive immunoreactivity for myosin, is increased in dogs treated with androstenedione; an effect which can be reversed by an aromatase inhibitor (Habenicht \& el Etreby 1991). Cell culture experiments have shown that oestradiol influences the expression of smooth muscle cell markers rather than stimulating cell growth, whereas dihydrotestosterone stimulated cell culture growth and had less influence on the expression of smooth muscle cell markers (Zhang et al. 1997). More recent cell culture experiments have also shown that sex hormones have varied effects on prostate smooth muscle cell contractility. Slight changes in the ratio of androgen to oestrogen have been shown to result in dramatic changes in calcium influx in prostatic stromal cells (Nguyen et al. 2007). Rather than changing ratios, an earlier study used single concentrations of oestradiol and testosterone and found that cell lines from different patients responded differently to hormone treatment, with some lines showing increased myosin expression after testosterone and oestradiol treatment and others showing no change (Smith et al. 2000).

The majority of our results do not imply that oestrogen affects prostate contractility, as perhaps age-associated changes in oestrogen receptors are also required to see changes in contractility. Two distinct populations of oestrogen receptors have been shown to be present in the prostate, oestrogen receptor $\alpha(\operatorname{ER} \alpha)$ and $\operatorname{ER} \beta . \operatorname{ER} \beta$ is localized to the epithelium while $\mathrm{ER} \alpha$ is distributed throughout the prostatic stroma (Royuela et al. 2001). The role of ER $\beta$ in mediating epithelial hyperplasia has been well documented in the ER $\beta$ knockout mouse prostate (Weihua et al. 2001). In the absence of ER $\beta$ signalling, mice develop epithelial hyperplasia due to increased epithelial proliferation and decreased apoptosis (Weihua et al. 2002, Imamov et al. 2004, McPherson et al. 2007). Recent studies of human prostate samples from patients suffering $\mathrm{BPH}$ have found that immunostaining for both $\operatorname{ER} \alpha$ and $\operatorname{ER} \beta$ is increased in the prostatic epithelium of BPH tissues (Royuela et al. 2001).

The results obtained in our concentration-response curves to tyramine showed that disruption of the aromatase gene may cause prostate tissues to release more noradrenaline in response to tyramine. This effect was only subtle and at first glance does not appear to be supported by the findings from our electrical field stimulation, noradrenaline concentration-response curves or SPG histochemistry. The differences observed may be the result of the way in which tyramine causes the release of noradrenaline. Electrical field stimulation-induced release of noradrenaline occurs via calcium-dependent, exocytotic mechanisms; whereas tyramine-induced release of noradrenaline is neither calcium dependent nor exocytotic. Although the density of noradrenergic innervation appears similar in all genotypes, the increase in absolute size of the prostate may mean that there is more total noradrenaline available to be released by tyramine. Alternatively, contractions of the mouse prostate in response to electrical field stimulation have a large non-adrenergic component (Gray \& Ventura 2005). This non-adrenergic component may be due to release of a nonadrenergic transmitter such as ATP which is known to be an excitatory co-transmitter with noradrenaline in the prostates of rats (Ventura et al. 2003) and guinea pigs (Buljubasich \& Ventura 2004); however, this is unlikely as we have previously shown the mouse prostate not to have a purinergic component to its electrical field stimulation-induced response (Gray \& Ventura 2005). These confounding factors may contribute to the masking of any subtle changes to adrenergic neurotransmission produced by changes in oestrogen levels. Noradrenaline is a directly acting agonist and its action would not be affected if changes are only occurring prejunctionally.

SPG fluorescence intensity was used as a measure of the number of noradrenaline-containing nerves present in the prostate. Noradrenaline levels were expected to have been increased in $\mathrm{ArKO}-/-$ prostates compared with $\mathrm{ArKO}+$ $/+$ prostates, with a corresponding increase in fluorescence intensity, however, this was not observed and indicates that our SPG histochemistry may not have been sensitive enough to detect such subtle changes in noradrenaline content.

In human clinical trials, aromatase inhibitors have had varied effects (Schweikert \& Tunn 1987, Schweikert et al. 1993, Gingell et al. 1995). The variability reported in the literature demonstrates the complex relationship between hormonal modulation of prostate growth and contractility. Aside from inhibiting oestrogen production, the absence of aromatase also increases the amount of testosterone (Fisher et al. 1998, McPherson et al. 2001). Our results suggest that aromatase is important in inhibiting prostate growth but appears to play only a subtle prejunctional role in prostate contractility in adult mice.

\section{Acknowledgements}

This work was supported by grants to $\mathrm{S} \mathrm{V}$ from the Ramaciotti Foundation, Appel Family Bequest, Arthur and Mary Osborn Estate and the NH and MRC (Australia). The authors have no conflict of interest that would prejudice the impartiality of this study. 


\section{References}

Bartsch G, Muller HR, Oberholzer M \& Rohr HP 1979 Light microscopic stereological analysis of the normal human prostate and of benign prostatic hyperplasia. Journal of Urology 122 487-491.

Belanger A, Candas B, Dupont A, Cusan L, Diamond P, Gomez JL \& Labrie F 1994 Changes in serum concentrations of conjugated and unconjugated steroids in 40- to 80-year-old men. Journal of Clinical Endocrinology and Metabolism 79 1086-1090.

Brodie AM, Banks PK, Inkster SE, Son C \& Koos RD 1990 Aromatase and other inhibitors in breast and prostatic cancer. Journal of Steroid Biochemistry and Molecular Biology 37 1043-1048.

Buljubasich R \& Ventura S 2004 Adenosine $5^{\prime}$-triphosphate and noradrenaline are excitatory cotransmitters to the fibromuscular stroma of the guinea pig prostate gland. European Journal of Pharmacology 499 335-344.

Ellem SJ, Schmitt JF, Pedersen JS, Frydenberg M \& Risbridger GP 2004 Local aromatase expression in human prostate is altered in malignancy. Journal of Clinical Endocrinology and Metabolism 89 2434-2441.

Farnsworth WE 1999 Estrogen in the etiopathogenesis of BPH. Prostate 41 263-274.

Fisher CR, Graves KH, Parlow AF \& Simpson ER 1998 Characterization of mice deficient in aromatase (ArKO) because of targeted disruption of the cyp19 gene. PNAS 95 6965-6970.

Gingell JC, Knonagel H, Kurth KH \& Tunn UW 1995 Placebo controlled double-blind study to test the efficacy of the aromatase inhibitor atamestane in patients with benign prostatic hyperplasia not requiring operation. The Schering 90.062 Study Group. Journal of Urology 154 399-401.

Gray KT \& Ventura S 2005 Evaluation of the mouse prostate as a suitable model for the study of human prostate function. Journal of Pharmacological and Toxicological Methods 51 41-50.

Gray KT \& Ventura S 2006 Alpha1L-adrenoceptors mediate contractions of the isolated mouse prostate. European Journal of Pharmacology 540 155-161.

Habenicht UF \& el Etreby MF 1991 Rationale for using aromatase inhibitors to manage benign prostatic hyperplasia. Experimental studies. Journal of Andrology 12 395-402.

Hiramatsu M, Maehara I, Ozaki M, Harada N, Orikasa S \& Sasano H 1997 Aromatase in hyperplasia and carcinoma of the human prostate. Prostate 31 118-124.

Imamov O, Morani A, Shim GJ, Omoto Y, Thulin-Andersson C, Warner M \& Gustafsson JA 2004 Estrogen receptor beta regulates epithelial cellular differentiation in the mouse ventral prostate. PNAS 101 9375-9380.

Jarred RA, Cancilla B, Prins GS, Thayer KA, Cunha GR \& Risbridger GP 2000 Evidence that estrogens directly alter androgen-regulated prostate development. Endocrinology 141 3471-3477.

Kaburagi Y, Marino MB, Kirdani RY, Greco JP, Karr JP \& Sandberg AA 1987 The possibility of aromatization of androgen in human prostate. Journal of Steroid Biochemistry 26 739-742.

Krieg M, Nass R \& Tunn S 1993 Effect of aging on endogenous level of 5 alpha-dihydrotestosterone, testosterone, estradiol, and estrone in epithelium and stroma of normal and hyperplastic human prostate. Journal of Clinical Endocrinology and Metabolism 77 375-381.

Lacey JP, Donatucci CF, Price DT, Page SO, Bennett SA, Tenniswood MP \& Schwinn DA 1996 Effects of androgen deprivation on prostate alpha 1-adrenergic receptors. Urology 48 335-341.

Matzkin H \& Soloway MS 1992 Immunohistochemical evidence of the existence and localization of aromatase in human prostatic tissues. Prostate 21 309-314.

McPherson SJ, Wang H, Jones ME, Pedersen J, Iismaa TP, Wreford N, Simpson ER \& Risbridger GP 2001 Elevated androgens and prolactin in aromatase-deficient mice cause enlargement, but not malignancy, of the prostate gland. Endocrinology 142 2458-2467.

McPherson SJ, Ellem SJ, Simpson ER, Patchev V, Fritzemeier KH \& Risbridger GP 2007 Essential role for estrogen receptor beta in stromalepithelial regulation of prostatic hyperplasia. Endocrinology 148 566-574.
Means GD, Mahendroo MS, Corbin CJ, Mathis JM, Powell FE, Mendelson CR \& Simpson ER 1989 Structural analysis of the gene encoding human aromatase cytochrome P-450, the enzyme responsible for estrogen biosynthesis. Journal of Biological Chemistry 264 19385-19391.

Nguyen ST, Prakash R, Anderson CJ, Frydenberg M \& Haynes JM 2007 Sex steroids modulate alpha(1)-adrenoceptor-stimulated $\mathrm{Ca}(2+)$ elevation in human cultured prostatic stromal cells. Prostate 67 74-82.

Royuela M, de Miguel MP, Bethencourt FR, Sanchez-Chapado M, Fraile B, Arenas MI \& Paniagua R 2001 Estrogen receptors alpha and beta in the normal, hyperplastic and carcinomatous human prostate. Journal of Endocrinology 168 447-454.

Schulze H \& Claus S 1990 Histological localization of estrogen receptors in normal and diseased human prostates by immunocytochemistry. Prostate 16 331-343.

Schweikert HU \& Tunn UW 1987 Effects of the aromatase inhibitor testolactone on human benign prostatic hyperplasia. Steroids 50 191-200.

Schweikert HU, Tunn UW, Habenicht UF, Arnold J, Senge T, Schulze H, Schroder FH, Blom JH, Ennemoser O, Horniger W et al. 1993 Effects of estrogen deprivation on human benign prostatic hyperplasia. Journal of Steroid Biochemistry and Molecular Biology 44 573-576.

Shibata Y, Ito K, Suzuki K, Nakano K, Fukabori Y, Suzuki R, Kawabe Y, Honma S \& Yamanaka H 2000 Changes in the endocrine environment of the human prostate transition zone with aging: simultaneous quantitative analysis of prostatic sex steroids and comparison with human prostatic histological composition. Prostate 42 45-55.

Smith P, Rhodes NP, Ke Y \& Foster CS 2000 Modulating effect of estrogen and testosterone on prostatic stromal cell phenotype differentiation induced by noradrenaline and doxazosin. Prostate 44 111-117.

Tan MO, Karabiyik I, Uygur MC, Diker Y \& Erol D 2003 Serum concentrations of sex hormones in men with severe lower urinary tract symptoms and benign prostatic hyperplasia. International Urology and Nephrology 35 357-363.

de la Torre JC \& Surgeon JW 1976 A methodological approach to rapid and sensitive monoamine histofluorescence using a modified glyoxylic acid technique: the SPG method. Histochemistry 49 81-93.

Ventura S, Dewalagama RK \& Lau LC 2003 Adenosine 5'-triphosphate (ATP) is an excitatory cotransmitter with noradrenaline to the smooth muscle of the rat prostate gland. British Journal of Pharmacology 138 1277-1284.

Walden PD, Gerardi C \& Lepor H 1999 Localization and expression of the alpha1A-1, alpha1B and alpha1D-adrenoceptors in hyperplastic and nonhyperplastic human prostate. Journal of Urology 161 635-640.

Weihua Z, Makela S, Andersson LC, Salmi S, Saji S, Webster JI, Jensen EV, Nilsson S, Warner M \& Gustafsson JA 2001 A role for estrogen receptor beta in the regulation of growth of the ventral prostate. PNAS $\mathbf{9 8}$ 6330-6335.

Weihua Z, Lathe R, Warner M \& Gustafsson JA 2002 An endocrine pathway in the prostate, ERbeta, AR, 5alpha-androstane-3beta,17beta-diol, and CYP7B1, regulates prostate growth. PNAS 99 13589-13594.

Yamada S, Ashizawa N, Ushijima H, Nakayama K, Hayashi E \& Honda K 1987 Alpha-1 adrenoceptors in human prostate: characterization and alteration in benign prostatic hypertrophy. Journal of Pharmacology and Experimental Therapeutics 242 326-330.

Zhang J, Hess MW, Thurnher M, Hobisch A, Radmayr C, Cronauer MV, Hittmair A, Culig Z, Bartsch G \& Klocker H 1997 Human prostatic smooth muscle cells in culture: estradiol enhances expression of smooth muscle cell-specific markers. Prostate 30 117-129.

\section{Received in final form 18 September 2007 Accepted 28 September 2007 Made available online as an Accepted Preprint 1 October 2007}

